\title{
Towards better internet bandwidth subscription in plateau state university
}

\begin{abstract}
Subscription of internet bandwidth for a public University's use is always faced with challenges of questions raised by the management and users. Such questions of which could be on why a slow internet speed and why extra money would have to be spent for better bandwidth subscription before experiencing improved internet speed. This research was necessitated by the urgent need to subscribe for a better Internet bandwidth compared to the current one on the network of Plateau State University Bokkos (PSU). In this paper we investigate the existing bandwidth on the network by interviewing the technical Staff on the history of bandwidth subscription and their respective Internet Service Providers (ISPs). This is to find out what service was subscribed for and from which ISP. Also comparing their services for better technical recommendation. Salem University Lokoja (SUL) was also investigated for comparative analysis, towards better recommendation. From the comparative analysis, services from some ISPs where better than others. Based on interview results and analysis, some observations were made and recommendation for ISPs and bandwidth was made also. The results of this study showed that some of the ISPs' bandwidth provision was good and cost-effective. Hence, Plateau State University needs to opt out of free services that could not deliver, for a cost-effective service that can provide improved learning and research.
\end{abstract}

Keywords: internet service, bandwidth subscription, isps, teleconsulting
Volume 7 Issue 3- 2018

\author{
Datukun Kalamba Aristarkus,' Sellappan \\ Palaniappan ${ }^{2}$ \\ 'Plateau State University Bokkos, Nigeria \\ 2 Malaysian University of Science and Technology, Malaysia
}

Correspondence: Datukun Kalamba Aristarkus, Plateau State University Bokkos, Nigeria,

Email kalamba.datukun@pg.must.edu.my

Received: February 26, 2018 | Published: June 22, 2018

\section{Introduction}

The abundance of Internet bandwidth of a Local Area Network (LAN), in Gigabit/sec, with minimal latency (less than $1 \mathrm{~ms}$ ) and also, if the packets drop rate was minimized, makes the throughput to be relatively high. When a number of users become far higher than the available bandwidth, latency, delay in traffic delivery becomes unavoidable. In this case the applications are fast with the performance regarded as good, ${ }^{1}$ with low latency. It is important to investigate if there has been better bandwidth subscribed for and also if the ISPs have been better ones. Internet service problems ${ }^{2}$ could be emanating from the quality of Internet bandwidth and also the trust-worthiness of the ISPs. Studying the effect of quality bandwidth and reliable ISPs, which has impact on the performance of the network ${ }^{3}$ is necessary in this study.

\section{Literature review}

To determine ways to achieve maximum throughput while delivering services to distant end-users at the same level of efficiency similar to those that exists closer to a typical LAN's ${ }^{4}$ in terms of Internet service delivery, available bandwidth and ISP must be reliable. The major cause of network degradation is when the workload equates to or became greater than the channel capacity, leading to congestion across the LAN, which results to bottleneck ${ }^{5}$ in the rate of delivery of Internet Service. Data transfer time ${ }^{6}$ can be high depending on the quality of bandwidth and ISP.

In 2009 alone, Nigerian banks achieved up to 30percent cost savings, Manufacturing Companies 25percent and Schools about 20percent cost saving on WAN recurrent costs through bandwidth optimization and management. ${ }^{7}$ This paper looked at the history of bandwidth subscriptions, comparing two Universities for dictating various subscriptions and their ISPs. What caused network bottleneck in a network ${ }^{8}$ is worth investigating the quality of subscribed bandwidth and ISP. The world of telecommunications has changed dramatically as a result of the rapid expansion of the Internet. ${ }^{9}$ Before the advent of ICTs, University Libraries were using manual service systems for a variety of reasons; adequacy in storage, access and retrieval of massive volume of information. ${ }^{10}$

Optimum load for a given LAN link carrying voice, video and data traffic Miroslaw et al., ${ }^{11}$ is ideal of a University Campus. Simulating the LAN network under different load conditions and extracted network performance statistic from real time network statistic for further analysis to show the effect of latency, jitter, packet drop, number of clients and limited bandwidth on the quality of service of applications running across the LAN ${ }^{12}$ could also be useful. But, the quality of service (QoS), Internet Service in particular is being much concerned with in terms of the quality of service and reliability of ISPs.

\section{Methodology}

It is important to provide a platform for quality in bandwidth subscription for University use. Thus, the bandwidth subscription of the University's Internet was examined by carrying out a survey, interviewing the technical Staff for the bandwidth subscription trend. This is to verify the quality of bandwidth subscription and ISPs' reliability. Recommendation for better bandwidth subscription, based on the analysis results as part of the conclusion of the research will be given. 


\section{Results}

The results of this survey are tabulated and further graph-plotted as below (Table 1) (Table 2) (Figures 1-4).

Table I History of bandwidth internet subscription in salem university

\begin{tabular}{|c|c|c|c|c|c|c|}
\hline ISP/Agent & $\begin{array}{l}\text { Bandwidth } \\
\text { (U/D) }\end{array}$ & Band & Duration & $\begin{array}{l}\text { Monthly } \\
\text { cost (N) }\end{array}$ & Reason for change & Service remark \\
\hline DOPC through Maxfront & $\begin{array}{l}256 \mathrm{kbps} / 256 \mathrm{kbps}- \\
\text { dedicated }\end{array}$ & C-band & $2008-2009$ & 300,000 & Rose from 300,000 to 500,000 plus & Very good \\
\hline DOPC- Maxfront & $\begin{array}{l}256 \mathrm{kbps} / 256 \mathrm{kbps}- \\
\text { dedicated }\end{array}$ & KU-band & 2009 & 300,000 & High failure during raining season & $\begin{array}{l}\text { Good with } \\
\text { normal weather }\end{array}$ \\
\hline Sky-Vision through Bologi & $\begin{array}{l}\text { I28kbps/256 \& } \\
\text { 384/5 I 2-dedicated }\end{array}$ & C-band & 2010 & 350,000 & Depreciated service & Good \\
\hline Lightening Networks & $\begin{array}{l}256 \mathrm{kbps} / 5 \mathrm{I} 2 \mathrm{kbps}- \\
\text { shared }\end{array}$ & C-band & $\begin{array}{l}\text { October,2010- } \\
\text { December } 2010\end{array}$ & 250,000 & Never enjoyed service & $\begin{array}{l}\text { Very poor } \\
\text { service }\end{array}$ \\
\hline Vodacom (Gateway) & $\begin{array}{l}512 \mathrm{kbps} / \mathrm{Imeg}- \\
\text { dedicated }\end{array}$ & C-band & June $20 \mathrm{II}-20 \mathrm{I} 2$ & 600,000 & Costly to maintain & Very good \\
\hline ASCOM & $512 / \mathrm{Imeg}$ & C-band & $2012-2013$ & 600,000 & Costly to maintain & Very good \\
\hline Coolink & $3 / 5 \mathrm{MB}$ & Ka-band & 2013 & 280,000 & $\begin{array}{l}\text { Serves only } 10 \text { users (average) per } \\
\text { time out of hundreds of users }\end{array}$ & good \\
\hline
\end{tabular}

Table 2 History of bandwidth internet subscription in plateau state university

\begin{tabular}{lllllll}
\hline ISPIAgent & Bandwidth (U/D) & Band & Duration & $\begin{array}{l}\text { Monthly cost } \\
\text { (N) }\end{array}$ & Reason for change & $\begin{array}{l}\text { Service } \\
\text { remark }\end{array}$ \\
\hline NCC-Government Agency & I28kbps-Shared & VSAT: C-band & $2007-D a t e$ & free & No change yet & Very poor \\
\hline
\end{tabular}

\section{Discussion}

The history of internet subscriptions covers only for two Universities, PSU and SUL in particular. Table 1 show that of SUL, which is more detailed and varying while that of PSU in Table 2 shows a kind of unprogressive subscription. From the two Tables, we will see that C-band was used by the two Universities, $\mathrm{Ku}$ band and $\mathrm{Ka}$ by SUL. We will observe that PSU has been on a very low bandwidth (128Kbps), which has even been shared. But, that of SUL has been changing, whose highest one was $512 / 1 \mathrm{Meg}$ on C-band, giving them the best service, carrying more users, among all their subscriptions. $512 \mathrm{Kbps}$ was for upload whereas $1 \mathrm{meg}$ for download accordingly.

Figure 1 shows that the PSU had the lowest bandwidth of the internet bandwidth, which have even been free (from NCC, a Government Agency). We understand from experience that as users increases, the load on the network increases and as the load on a network increases, speed reduces due to congestion. Therefore, bandwidth is a considerable factor in ascertaining the performance of a network. Here, we say that throughput is an integral part of bandwidth as bandwidth corresponds to entire capacity and through a rate transmissible.

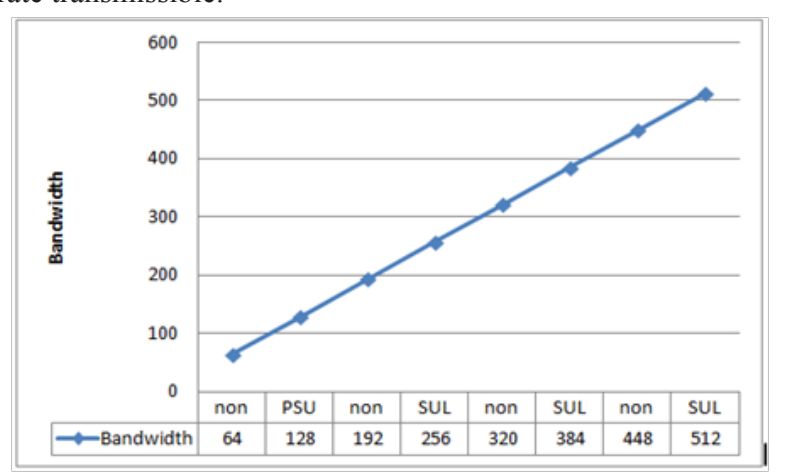

Figure I bandwidth used by Universities
Figure 2 described the fact that SUL bandwidth highest upload was about $512 \mathrm{Kbps}$, which is reflected in Table 1. Noting also from Table 1 that the download is higher, which is 1 Mbps. The bandwidth of PSU is just about 128 as reflected in Table 2 as both the download and upload alike. We will therefore note that what PSU uses as both Up and down load is not even up to that of SUL's highest download so far.

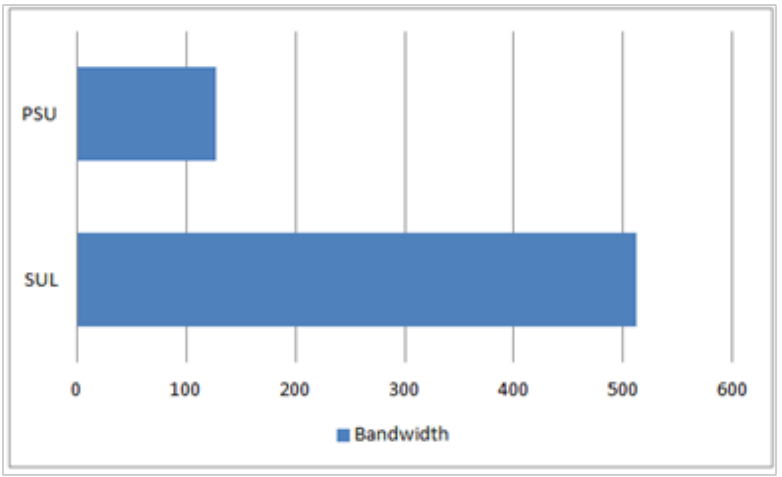

Figure 2 Bandwidth bar chart.

Considering Figure 3, we will see that each of the ISPs had their cost of bandwidth, ranging from 200,000 naira to 600,000 naira. Some were found to be costly while others cheep. The free service used by PSU have not been good for learning and research, better of which is that of SUL. Despite the fact that SUL has more bandwidth and spent more on subscriptions, it still scouts for more, seeking cost effectiveness. Figure 4 explains that some of the services were expensive but still good enough to go with provided afforded to be maintained. Some were cheaper, yet with still good service compare to some of the expensive ones that may not be too good. 


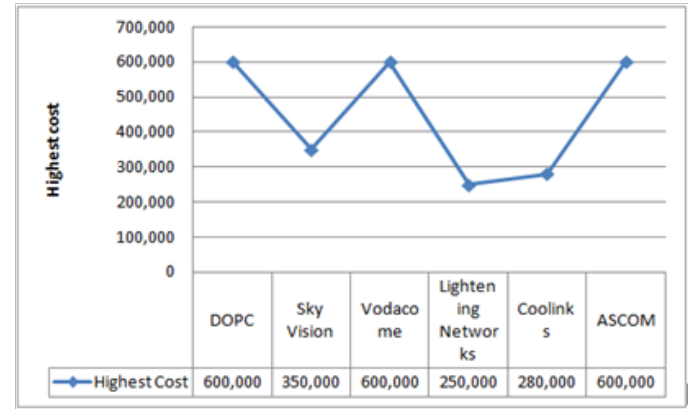

Figure 3 Highest bandwidth cost.

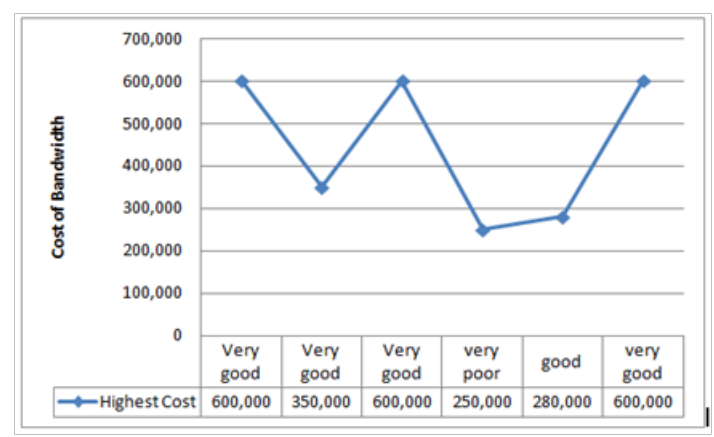

Figure 4 Comparing cost of bandwidth and quality of service.

\section{Conclusion}

From the analysis of our data so far, SUL have always had better bandwidth, but kept changing subscription to gain better service at a manageable rate. This is might have helped them to know which ISP is better in terms of service delivery. We saw from our analysis that the free bandwidth used by PSU has delivered no reasonable service to the users. Also, Table $1 \&$ Figure 4 tells us that a good service may not necessarily be expensive. Hence the need for Plateau State University to opt out of free service by subscribing an affordable service, a cost-effective one, for better academic and other use in the system is necessary. Better internet bandwidth would further help the university get remote medical consulting (teleconsulting) for teaching and treatments on video conferencing.

\section{Acknowledgements}

None.

\section{Conflict of interest}

Author declares that there is no conflict of interest.

\section{References}

1. Ian Molyneaux. The Art of application performance testing Publisher: O Reilly Media Inc. Journal of Emerging Trends in Engineering and Applied Sciences (JETEAS). 2009;2(3):482-486.

2. Addison Wesley. Network latency effects on application performance. 2006 .

3. Kimberly C Claffy, Constantinos Dovrolis. Bandwidth estimation: measurement methodology and applications. DOE SCiDAC Proposal. 2001.

4. Tony Kenyon, Elaina Kenyon. High performance Data Network Design: Design Techniques and Tools (IDC Technology). Digital Press. 2002.

5. Mohd Naziri Ismail,Abdullah MohdZin. Traffic Engineering: Simulation model and real network Environment over single and multiple links. European Journal of Scientific Research . 2009;25(1):54-67.

6. Sanjay K Bose. An Introduction to Queuing Systems. New York: Kluwer Academic/Plenum; 2002.

7. John SN, Okonigene RE, Akinade BA, et al. Optimized Remote Network Using Specified Factors as Key Performance Indices. Global Journal of Computer Science and Technology. 2010;10(5):14-17.

8. Hu TC, Tolendino LF. Network Protocol Changes can improve DisCom WAN Performance: Evaluating TCP modifications and SCTP in the ASC Tri-lab Environment. Sandia Report. 2005.

9. https://www.cisco.com/c/dam/en us/about/ac123/ac147/archived issues/ipj_15-2/ipj_15-2.pdf

10. Oduwole AA, Akpati CB. Accessibility and retrieval of electronic information at the University of Agriculture Library, Abeokuta, Nigeria. Library review. 2003;52(2):228-233.

11. Miroslaw Narbutt, Mark Davis. Effect of free bandwidth on VOIP performance in 802. 116 WLAN networks. Dublin: IEE Irish Signal and Systems Conference, Dublin, Ireland; 2006.

12. Giovonni Giambene. Queuing theory and Telecommunication networks application. 1st ed Berlin: Springer; 2005. 